\title{
Correspondence
}

\section{Succinylcholine use in emergency eye operations}

To the Editor:

Drs. Cunningham and Barry ${ }^{2}$ are to be congratulated for their succinct account of the implications of general anaesthesia in ophthalmic surgery. In particular, they rationally addressed the question of succinylcholine use in emergency eye operations, a problem foremost in our minds when dealing with such situations. They correctly stated that no method of "pretreatment" offers guarantee of protection from the intraocular hypertensive effects of succinylcholine but nevertheless argued that this is the best drug to use. While we wholeheartedly agree with their conclusions, we believe that they have omitted to mention what is one of the most important arguments in favour of the use of succinylcholine in emergency eye surgery.

There is little argument that tracheal intubation should be undertaken in these patients. That this should be performed under the best possible conditions for the safety of the patient is similarly not in doubt. Succinylcholine is the best neuromuscular blocking agent for this purpose. The fact is that the effect of laryngoscopy and tracheal intubation on both intraocular and intracranial pressure is of such magnitude as to render the succinylcholine effect almost inconsequential. There are ample studies to attest this fact ${ }^{2-7}$ and that the best and safest technique would therefore include the use of this drug. It is clear from these studies that greater attention must be directed towards modification of the effects of laryngoscopy and tracheal intubation and away from the exhausted "succinylcholine controversy." Our ultimate concern is for the patient at all times rather than for the individual eye.

Dermot F. Murphy fFarcsi

Neville J. Davis Ffarcs FFaracs

Department of Anaesthesia and Intensive Care

Sir Charles Gairdner Hospital, Nedlands

Western Australia, 6009

\section{REFERENCES}

1 Cunningham $A J$, Barry $P$. Intraocular pressure -

physiology and implications for anaesthetic managenent.

Can Anaesth Soc J 1986; 33: 195-208.

2 Murphy DF, Eustace P, Unwin A, Magner JB. Atra- curium and intraocular pressure. Br J Ophthalmol 1985; 69: $673-5$.

3 Sia RL, Rashkovsky OM. Org NC45 and intraocular pressure during anaesthesia. Acta Anaesthesiol Scand 1981; 25: 219-21.

4 Couch JA, Eltringham RJ, Magauran, DM. The effect of thiopentone and fazadinium on intraocular pressure. Anaesthesia $1979 ; 34: 586-91$.

5 Murphy DF. Eustace P. Unwin A, Magner JB. Intravenous lignocaine pretreatment to prevent the intraocular pressure rise following suxamethonium and tracheal intubation. Br J Ophthalmol 1986 (in press).

6 Hamill JF, Bedford RF, Weaver DC. Colohan AR. Lidocaine before endotracheal intubation: intravenous or laryngotracheal. Anesthesiology, 1981; 55: 578-81.

7 Libonati MM, Leahy $J L$, Ellison $N$. The use of succinylcholine in open eye surgery. Anesthesiology 1985; 62: $637-40$.

\section{$R E P L Y$}

The authors appreciate the comments of Doctors Murphy and Davis. In recent years, a significant change in emphasis has emerged in the ancesthetic management for emergency repair of a penetrating eye injury.

Norwithstanding theoretical objections, Libonati et al.,' Dunion. ${ }^{2}$ Bourke, ${ }^{3}$ have been prepared to state publicly and substaniate with data what many anaesthetisss have kHown and practiced for years - a carefuily controiled rapid sequence induction using succinylcholine is a rational and safe method of induction for a patient with an open eye and full stomach.

The prognosis for restoration of useful vision following surgical repair of perforated eye injuries has improved dramatically over the past decade. With advanced vitreoretinal surgical teciniques. 54 per cent of 278 patients aggressively treated regained a visual acuity of $20 / 100$ or better within six months. ${ }^{4}$ Besides perioperative considerations, the prognosis for binocular vision depends on whether the injury involved the anterior chamber andior posterior segment, whesher there was uveal prolapse and whether intraocular reaction occurred. ${ }^{5}$ Anaesthetic management must reflect the high priority for potential restoration of useful binocular vision.

With the development of "priming techniques" to accelerate the onset of non-depolarizing relavants, attempts have been made to accomplish a "rapid sequence" emergency intubarion with non-depolarizing agents. Unfortunately, in studies designed to simulate rapid sequence induction with thiopentone $5.0 \mathrm{mg} \cdot \mathrm{kg}^{-1}$ and vecuronium $0.2 \mathrm{mg} \cdot \mathrm{kg}^{-1}$ or atracuronium $1.0 \mathrm{mg} \cdot \mathrm{kg}^{-1}$ using pneumotonometry ${ }^{6}$ and others using thiopentone $5.0 \mathrm{mg} \cdot \mathrm{kg}^{-1}$ and atracurium $0.75 \mathrm{mg} \cdot \mathrm{kg}^{-1}{ }^{7}$ significant elevations of intraocular pressure were observed following laryngoscopy and intubation. Pre-treatment schedules empioying $1-2 \mathrm{mg} \cdot \mathrm{kg}^{-1}$ lidocaine, while attenuating the haemodyna. mic responses to laryngoscopy and intubation, proved dis- 
appointing in blunting the intraocular hypertensive response to succinylcholine and intubation ${ }^{8}$ but were more promising when administered prior to pancuronium. ${ }^{9}$ Other pretreatment regimes, i.e., beta blockers, calcium channel antagonists, narcotics, prior to rapid sequence induction may prove a fruitful area of investigation.

When confronted with the clinical situation, the best advice in Murphy's own words ${ }^{10}$ is "the anesthesiologist must balance the overall risk to the patient with the risk to the injured eye, in deriding if succinylcholine is to be used."

Anthony J. Cunningham MB FFARCS FRCPC

Peter Barry MB FRCS

Departments of Anaesthesia and Ophthalmology

St. Vincents Hospital

Elm Park

Dublin 4, Ireland.

\section{REFERENCES}

1 Libonati $M M$, Leahy $J L$, Ellison $N$. The use of succiny]choline in open eye surgery. Anesthesiology 1985; 62: 637-40.

2 Donlon JV. Succinylcholine and open eye injury. Anesthesiology 1986; 64: 525-6.

3 Bourke DL. Open eye injuries. Anesthesiology 1985; 63: 727.

4 Rich AL. Witherspoon CD. Morris RE. Feist RM. Use of non depolarizing anesthetic agents in penetrating ocular injuries. Anesthesiology 1986; 65: 108-9.

5 Weiner $M J$, Olk RJ. Anesthesia for open eye surgery. Anesthesiology 1986; 65: 109-10.

6 Schneider MJ, Stirt JA, Einholt DA. Atracurium, Vecuronium and intraocula rpressure in humans. Anesth Anaig 1986; 65: 877-82.

7 Lavery GG, McGalliard JN, Mirakhur RK, Shepherd WFI The effects of atracurium on intraocular pressure during steady state anaesthesia and rapid sequence induction: a comparison with succinylcholine. Can Anaesth Soc J 1986; 33: 437-42.

8 Smith RB, Babinski $M$, Leano $N$. The effect of lidocaine on succinylcholine-induced rise in intraocular pressure Can Anaesth Soc J 1979; 26: 482-3.

9 Lerman J, Kiskis AA. Effects of intravenous ]idocaine and high dose pancuronium on intraocular pressure in children (Abstract) Anesth Analg 1985; 64: 245 .

10 Murphy $D F$. Anesthesia and intraocular pressure. Anesth Analg 1985; 64: 520-30.

\section{Water trap for fresh gas flow line of Bain or CPRAM Circuit}

To the Editor:

Significant heat and water loss can occur during anaesthesia in infants and children when dry gases are utilized. Dry gases cause heat loss through evaporation from the lungs. For every gram of water vaporized, $\mathbf{5 8 0}$ calories must be supplied by the patient. ' Dry gases may also cause pathological alterations in the morphology and function of

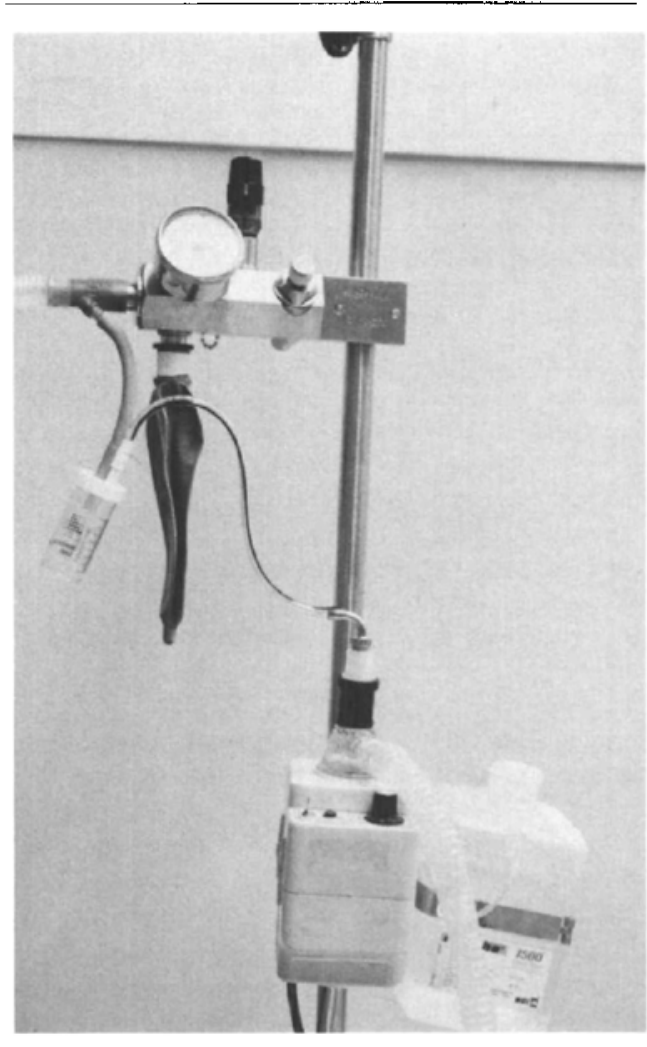

FIGURE Improvised water trap placed between humidifier and breathing cincuit.

pulmonary ciliated epithelium and in pulmonary mechanics. ${ }^{2}$ Use of a humidified and heated flow of gases has been shown to limit heat and water loss and on occasion provide heat input. ${ }^{3}$

For cases longer than one hour, we frequently use an exogenous heat and humidification source. Heating the reservoir water will increase the degree of humidification. Heated water vapour can cause marked condensation in the fresh gas flow (FGF) line and inner fresh gas tube of the Bain or controlled partial rebreating anaesthesia method (CPRAM) circuits. Even with care to avoid overheating, some condensation may still occur.

Condensed water in the FGF line is a possible danger to the patient as this could cause obstruction of gas flow or even reach the patient, causing aspiration. We have developed a condensed water trap (Figure), made by connecting a "specimen trap" in the line from the humidifier to the FGF line of the Bain or CPRAM circuits. 